\title{
Tularemi Salgını ve Sonrası; Mevsimsel Değişikliklerin Etkisi
}

\section{Tularemia Outbreak and After; Effect of Seasonal Changes}

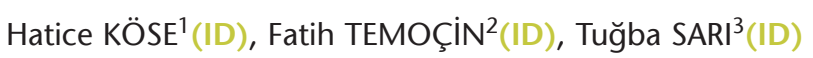 \\ ${ }^{1}$ Yozgat Şehir Hastanesi, Enfeksiyon Hastalıkları ve Klinik Mikrobiyoloji Kliniği, Yozgat. \\ 1 Yozgat City Hospital, Department of Infectious Diseases and Clinical Microbiology, Yozgat, Turkey. \\ ${ }^{2}$ Ondokuz Mayıs Üniversitesi Tıp Fakültesi, Enfeksiyon Hastalıkları ve Klinik Mikrobiyoloji Anabilim Dalı, Samsun. \\ 2 Ondokuz Mayis University Faculty of Medicine, Department of Infectious Diseases and Clinical Microbiology, \\ Samsun, Turkey. \\ ${ }^{3}$ Pamukkale Üniversitesi Tıp Fakültesi, Enfeksiyon Hastalıkları ve Klinik Mikrobiyoloji Anabilim Dalı, Denizli. \\ 3 Pamukkale University Faculty of Medicine, Department of Infectious Diseases and Clinical Microbiology, Denizli, Turkey.
}

* Bu çalışma, XIX. Türk Klinik Mikrobiyoloji ve Infeksiyon Hastalıkları Kongresi (28-31 Mart 2018, Antalya)’nde sözel sunum olarak sunulmuştur.

Makale Atıfı: Köse H, Temoçin F, Sarı T. Tularemi salgını ve sonrası; mevsimsel değişikliklerin etkisi. Mikrobiyol Bul 2020;54(2):203-210.

\section{ÖZ}

Tularemi, Francisella tularensis'in neden olduğu zoonotik bir enfeksiyon hastalığıdır. Yozgat ilinde ilk olgu 2009 yılında bildirilmiş olup, 2010 ve 2016 yılları arasında 525 olgu görülmüştür. Toplam 442 olgu ile 2010 ve 2011 yıllarında salgın yaşanmıştır ve sonraki yıllarda olgu sayısı azalmıştır. Bu çalışmada, Yozgat ilinde 2010-2011 yıllarında görülen tularemi salgınının ve takip eden yıllarda olgu sayılarının azalışının mevsimsel faktörlerle (sıcaklık, nem, yağış miktarı, rüzgar hızı) olan ilişkisinin incelenmesi amaçlanmıştır. Bu çalışmaya 2010-2016 yılları arasında görülen tularemi olguları dahil edilmiştir. Uyumlu klinik bulgular varlığında, mikroaglütinasyon testi (MAT) $\geq 1 / 160$ veya en az iki hafta ara ile bakılan MAT titresinde dört kat artış olması, tularemi olarak tanımlanmışır. Yozgat ili Meteoroloji Müdürlüğünden elde edilen aylık en yüksek, en düşük ve ortalama sıcaklık ile aylık ortalama rüzgar hızı, ortalama nem oranı ve yağış miktarı bilgileri kaydedilmiştir. Verilerin normal dağılıma uygunluğu Shapiro-Wilk testi ile değerlendirilmiştir. Bağımsız iki grubun nicel verilere göre birbiriyle karşıaştırılmasında Mann-Whitney U testi Monte Carlo sonuçlarıyla birlikte kullanılmıştır. Nicel değişkenler tablolarda ortalama \pm "Interquartile Range (IQR)" kategorik değişkenler ise $n$ (\%) olarak gösterilmiştir. Değişkenler \%95 güven düzeyinde incelenmiş olup p $<0.05$ anlamlı kabul edilmiştir. Yozgat ilinde, 2010-2016 yıllarında görülen 525 tularemi olgusu incelenmiştir. Tularemi olgularının ilkbahar ve kış aylarında daha fazla görüldüğü saptanmıştır. Meteorolojik verilerden rüzgar şiddetinin salgın görülen yıllarda, diğer yıllara göre istatistiksel olarak anlamlı derecede fazla olduğu saptanmıştır $(p<0.05)$. Ortalama sıcaklık, yağış miktarı ve nem değerlendirildiğinde istatistiksel olarak anlamlı bir fark saptanmamıştır ( $p>0.05$ ). Çalışmamızda, tularemi salgınının görüldüğü yıllarda rüzgar hızının diğer yıllara oranla anlamlı derecede yüksek olduğu saptanmışır $(p<0.05)$ ve bu yükseklik kene popülasyonunun sayısı ve dağılımında artışa neden olmuş olabilir. Artan kene popülasyonunun,

Iletişim (Correspondence): Dr. Öğr. Üyesi Fatih Temoçin, Samsun Ondokuz Mayıs Üniversitesi Tıp Fakültesi, Enfeksiyon Hastalıkları ve Klinik Mikrobiyoloji Anabilim Dalı, Samsun, Türkiye. Tel (Phone): +90 3623121919 ,

E-posta (E-mail): ftemucin@yahoo.com.tr 
tulareminin insanlara doğrudan bulaşından çok, kemirici ve evcil hayvanlara bakteri geçişini sağlayarak, tulareminin yaşam döngüsünün devamlıı̆̆ında anahtar rol oynadığını düşünüyoruz. Diğer meteorolojik değişkenlerde, ortalama sıcaklık, yağış miktarı ve nem oranı açısından ise istatistiksel olarak anlamlı bir fark saptanmamıştır ( $p>0.05)$.

Anahtar kelimeler: Francisella tularensis; tularemi; mevsimsel faktörler; rüzgar.

\section{ABSTRACT}

Tularemia is a zoonotic infectious disease caused by Francisella tularensis. In Yozgat, a total of 525 cases were identified between 2010 and 2016. A serious epidemic occurred with a total of 442 cases in 2010 and 2011 and the number of cases decreased in the later years. In our study, we investigated the association of seasonal factors (temperature, humidity, amount of precipitation, wind speed) with the tularemia epidemic which occurred in 2010 and 2011 and with the decrease in the number of cases in the later years. This study included tularemia cases seen in Yozgat and its districts between 2010 and 2016. Tularemia was defined as a microagglutination test (MAT) result of $\geq 1 / 160$ or a 4-fold increase in MAT titer between two tests at least two weeks apart, in the presence of consistent clinical findings. Seasonal factors were recorded. The conformity of data to normal distribution was analyzed using the ShapiroWilk test. The Mann-Whitney $U$ test was used with the results of Monte Carlo simulations to compare differences between two independent groups in terms of quantitative data. It was found that tularemia cases are more frequently seen in the spring and winter. Meteorological data showed that wind force was statistically significantly higher in the epidemic years than in the other years $(p<0.05)$. No statistically significant difference was found between mean air temperature, amount of precipitation, and humidity ( $p>0.05$ ). Our study found that wind velocity was significantly higher in the epidemic years than in the other years $(p<0.05)$ and this increase in wind velocity may have caused an increase in tick population and distribution. We believe that, rather than causing direct transmission of tularemia to humans, the increased tick population plays a key role in the maintenance of the life cycle of tularemia by causing transmission to rodents and domestic animals.

Keywords: Francisella tularensis; tularemia; seasonal factors; wind.

\section{Gíriş}

Tularemi Francisella tularensis'in neden olduğu ve yalnızca Kuzey Yarımkürede görülen zoonotik bir enfeksiyon hastalı̆ı̆ıır ${ }^{1}$. F.tularensis, intraselüler yerleşim gösteren, hareketsiz, gram-negatif bir kokobasildir. Coğrafi dağılım ve virülans farklıııları gösteren dört alt türü bilinmektedir; tularensis (tip A), holarctica (tip B), novicida ve mediasiacita. F.tularensis subsp. tularensis özellikle Kuzey Amerika'da görülen, aynı zamanda Avrupa'da da izole edilen ve virülansı en yüksek olan alttürdür. Avrupa'daki ve Türkiye'deki salgınlardan, virülansı daha az olan F.tularensis subsp. holarctica sorumludur ${ }^{2,3}$. Lagomorf ve kemiriciler önemli hayvan rezervuarlarıdır. Başlıca vektörleri keneler ve sivrisineklerdir. Diğer bulaş yolları ise, kontamine aerosoller, su ve gıdaların tüketilmesi ve hayvan ısırıklarıdır ${ }^{1}$. Tularemi, birçok ülkede ilkbahar sonu ve yaz aylarında sık görülürken, Türkiye'de sonbahar ve kış aylarında daha sık görülmektedir, ${ }^{1,4}$. Türkiye'de ilk tularemi olgusu 1936 yılında Trakya Bölgesinde görülmüştür ve sonraki yıllarda tüm bölgelerden olgular bildirilmiştir ${ }^{4,5}$. 1954-1988 yılları arasında hiç olgu bildirilmemiştir. Türkiye Cumhuriyeti Halk Sağlığı Genel Müdürlüğü verilerine göre, 2010-2016 yılları arasında Türkiye genelinde 5484 olgu bildirilmiştir. Türkiye'nin iç Anadolu Bölgesinde yer alan Yozgat ilinde ilk olgu 2009 yılında bildirilmiş olup, 2010-2016 yılları arasında 525 olgu görülmüştür. Toplam 
442 olgu ile 2010-2011 yıllarında ciddi bir salgın yaşanmıştır ve sonraki yıllarda olgu sayısı azalmıştır.

Enfeksiyon hastalıkları üzerine yapılan epidemiyolojik çalışmalarda, mevsimsel faktörlerin, hastalığın sıklığı ve coğrafi dağılımı üzerine önemli etkileri olduğu bilinmektedir6́ Bu çalışmada, Yozgat ilinde 2010-2011 yıllarında görülen tularemi salgınının ve takip eden yıllarda olgu sayılarının azalışının mevsimsel faktörlerle olan ilişkisi incelenmiştir. Tularemi olgularının epidemiyolojik özelliklerini ve yıllık ortalama sıcaklık, ortalama nem, yağış miktarı ve rüzgar hızının tularemi salgınları üzerine etkilerinin belirlenmesi amaçlanmıştır.

\section{GEREÇ ve YÖNTEM}

Bu çalışma, Yozgat il Sağlık Müdürlüğü onayı ile gerçekleştirildi (Tarih: 12.03.2020 ve Karar no: 9219857.030.01).

Bu çalışma, Yozgat ilinde görülen tularemi olguları ile mevsimsel faktörler arasındaki ilişkiyi inceleyen kesitsel bir çalışmadır. Yozgat, Türkiye'nin iç̧ Anadolu Bölgesinde yer almaktadır. Toplam yüz ölçümü 14123 km², 2016 yılı toplam nüfusu 421041'dir. Bu çaIışmaya, 2010-2016 yılları arasında Yozgat il ve ilçelerinde görülen tularemi olguları dahil edildi. Tularemi hasta verilerine, hastanemiz bilgi sistemi veri tabanı taranarak ve Yozgat il Sağlık Müdürlüğü kayıtları incelenerek ulaşıldı. Uyumlu klinik bulgular varlığında, mikroaglütinasyon testi (MAT) $\geq 1 / 160$ veya en az iki hafta ara ile bakılan MAT titresinde 4 kat artış olması tularemi olarak tanımlandı. Olgu sayıları ve hastaların epidemiyolojik bağlantıları dikkate alınarak 2010 ve 2011 yılları salgın yılı olarak değerlendirildi.

Yozgat ili Meteoroloji Müdürlüğünden, ilin dört ayrı noktasına kurulan meteoroloji ölçüm istasyonlarından elde edilen, aylık en yüksek, en düşük ve ortalama sıcaklık, aylık ortalama rüzgar hızı, ortalama nem oranı ve yağış miktarı bilgileri alındı. Hastaların yaş, cinsiyet, hastalık görülme tarihi, yaşadığı bölge verileri ve meteorolojik veriler "Statistical Package for the Social Sciences (SPSS) version 22.0 for Windows (IBM Corporatation, Armonk, New York, United States)"a kaydedildi.

\section{İstatistiksel Analiz}

Verilerin normal dağılıma uygunluğu Shapiro-Wilk testi ile değerlendirildi. Bağımsız iki grubun nicel verilere göre birbiriyle karşılaştırılmasında Mann-Whitney U testi Monte Carlo sonuçlarıyla birlikte kullanıldı. Nicel değişkenler tablolarda ortalama \pm "Interquartile Range (IQR)" kategorik değişkenler ise n (\%) olarak gösterildi. Değişkenler \%95 güven düzeyinde incelenmiş olup $\mathrm{p}<0.05$ anlamlı kabul edildi.

\section{BULGULAR}

Bu çalışmada, Yozgat ilinde, 2010-2016 yıllarında görülen 525 tularemi olgusu incelenmiş ve meteorolojik değişkenlerin olgu sayısı üzerine etkisini belirlemek amaçlanmıştır. Türkiye'de 2010 yılında 277 olgu ile bir salgın görülmüş ve 2011 yılında da 182 olgu ile devam etmiş, ancak takip eden yıllarda olgu sayıları çok azalmıştır. Olguların yıllara 
göre dağılımları ve nüfusa oranları Tablo l'de gösterilmiştir. Tularemi olgularının yaş ortalaması $37.7 \pm 18.3$ yıldır ve 283 (53.9\%)'ü kadındır. Salgın görülen yıllar (2010-2011) ile diğer yıllar (2012-2016) karşılaştııılı̆̆ında, tularemi hastalarının yaş ortalaması ve cinsiyet dağılımı açııından istatistiksel olarak anlamlı bir fark saptanmamıştır (Tablo II). Olgular en çok 21-40 yaş grubunda görülmüştür. Yaş grupları ve cinsiyete göre dağıım Şekil 1'de gösterilmiştir. Tularemi klinik formlarına bakıldığında 463 (\%88.1) olgu ile en sık orofaringeal form görülmüştür. Glandüler form 47 (\%8.9), ülseroglandüler form 12 (\%2.2) ve oküloglandüler form 3 (\%0.6) olguda saptanmıştır. Tifoidal ve pnömonik tularemi formları görülmemiştir. Tularemi olgularının ilkbahar ve kış aylarında daha fazla

\begin{tabular}{|lcccccccc}
\hline \multicolumn{10}{l|}{ Tablo I. Yıllara Göre Tularemi Olgu Sayıları ve Nüfusa Oranları } \\
\hline & \multicolumn{7}{c|}{$\mathbf{n}(\%)$} \\
\cline { 2 - 9 } Nüfus (n) & Toplam & $\mathbf{2 0 1 0}$ & $\mathbf{2 0 1 1}$ & $\mathbf{2 0 1 2}$ & $\mathbf{2 0 1 3}$ & $\mathbf{2 0 1 4}$ & $\mathbf{2 0 1 5}$ & $\mathbf{2 0 1 6}$ \\
\hline 421.041 & 525 & 277 & 182 & 21 & 5 & 3 & 15 & 22 \\
& $(12.4)$ & $(6.5)$ & $(4.3)$ & $(0.49)$ & $(0.11)$ & $(0.07)$ & $(0.35)$ & $(0.52)$ \\
\hline
\end{tabular}

\begin{tabular}{|lccc|}
\hline \multicolumn{4}{l}{ Tablo II. Tularemi Olgularının Demografik Özellikleri } \\
\hline & $\mathbf{2 0 1 0 - 2 0 1 1}$ & $\mathbf{2 0 1 2 - 2 0 1 6}$ & $\mathbf{p}$ \\
\hline Olgu sayııı (n) & 442 & 83 & \\
Cinsiyet (erkek/kadın) & $205 / 237$ & $37 / 46$ & 0.76 \\
Yaş ortalaması & $36.7 \pm 18.2$ & $40.7 \pm 18.7$ & 0.087 \\
\hline
\end{tabular}

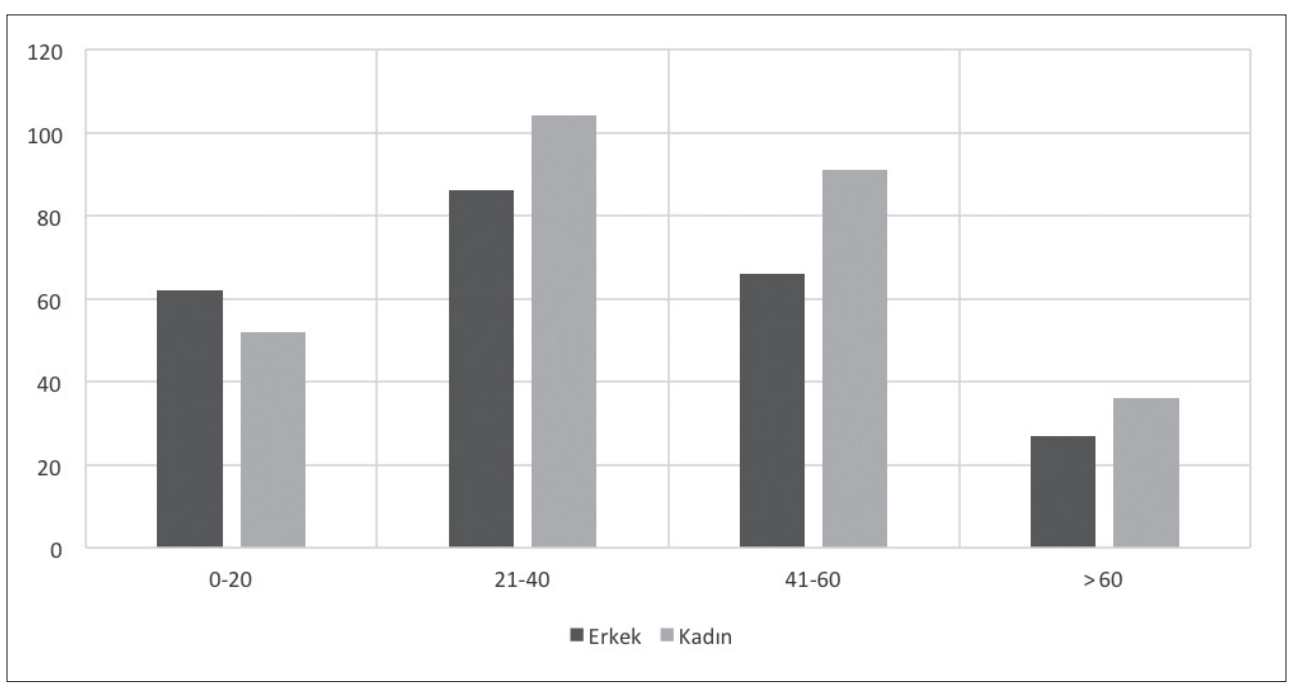

Şekil 1. Yaş gruplarına göre olguların dağııımı. 


\begin{tabular}{|lccc}
\hline \multicolumn{4}{l}{ Tablo III. Tularemi Olgularının Görüldüğü Yıllarda Saptanan Meteorolojik Verilerin Karşılaştııılması } \\
\hline & $\mathbf{2 0 1 0 - 2 0 1 1}$ & $\mathbf{2 0 1 2 - 2 0 1 6}$ & $\mathbf{p}$ \\
\cline { 2 - 4 } Yıllık ortalama & Ortanca \pm IQR & Ortanca \pm IQR & \\
\hline Sıcaklık $\left({ }^{\circ} \mathrm{C}\right)$ & $4.9 \pm 7.4$ & $5.3 \pm 10.8$ & 0.458 \\
Nem $(\%)$ & $70.6 \pm 17.3$ & $70.1 \pm 19.3$ & 0.364 \\
Rüzgar $(\mathrm{m} / \mathrm{sn})$ & $2 \pm 0.7$ & $1.9 \pm 0.4$ & $<0.001$ \\
Yağış $(\mathrm{mm} / \mathrm{sa})$ & $36.2 \pm 44.5$ & $35.9 \pm 46.9$ & 0.147 \\
\hline IQR: Interquartile Range. & & & \\
\hline
\end{tabular}

görüldüğü tespit edilmiştir. Salgın görülen yıllar ile olgu sayısının az olduğu diğer yıllar karşılaştırıldığında meteorolojik verilerden rüzgar şiddetinin salgın görülen 2010 ve 2011 yıllarında, diğer yıllara göre istatistiksel olarak anlamlı derecede fazla olduğu saptanmıştır $(p<0.05)$. Ortalama sıcaklık, yağış miktarı ve nem değerlendirildiğinde, analiz edilen yıllar arasında istatistiksel olarak anlamlı bir fark saptanmamıştır ( $p>0.05$ ) (Tablo III).

\section{TARTIŞMA}

Bu çalışmada 2010-2016 yılları arasında Yozgat ilinde toplam 525 tularemi olgusuna ulaşılmıştır. Literatür incelendiğinde, ülkemizde tularemi ilk kez 1936 yılında Trakya Bölgesinde bildirilmiştir 4,5. 1938-1954 yılları arasında Van, Lüleburgaz ve Antalya'dan üç salgın bildirilmiş7-9, 1988 yılına kadar tularemi görülmemiş, 1988-1998 yılları arasında Bursa'dan 250 olgu bildirimi yapılmıştır ${ }^{10}$. Sağlık Bakanlığı verilerine göre 2005 yılından önce 1000'den fazla olgu görülmüşken, 2005-2009 yılları arasında 1091 olgu bildirilmiştir $^{11}$. 2009 yılında 432, 2010 yılında 1531 olgu görülmüş olup, 2011 yılında pik yaparak 2151 olgu ile tüm Avrupa Birliği ülkelerinde görülenlerden daha fazla sayıda olgu görülmüştür. 2012 yılında ise 607 olgu görülmüş ve sonraki yıllarda azalarak devam etmiştir ${ }^{4}$. Yozgat ilinde ise 2009 yılından itibaren endemik olarak görülmeye başlamış ve Türkiye geneli ile uyumlu olarak olgu sayıları 2010-2011 yıllarında artmış, sonraki yıllarda azalarak devam etmiştir.

Türkiye'de tularemi epidemiyolojisini irdeleyen kapsamlı bir çalışmada, tularemi olgularının kadınlarda erkeklerden daha fazla görüldüğü bildirilmiştir ${ }^{11}$. Çalışmamızda da Yozgat'taki tularemi olgularının \%53.9'unun kadın olduğu görülmektedir. Bunun nedeninin kadınların ev işlerinde daha aktif olması, kontamine su ile temaslarının fazla olması ve gıda depolama alanlarında hayvan çıkartıları ve idrarı ile daha fazla temasının olması olarak açıklanabilir.

Tularemi olgularımız erişkin yaş grubunda daha çok görülmüştür ve en sık 20-40 yaş aralığındadır. Ülke geneline bakıldığında 2005-2009 yılları arasında görülen tularemi olgularının büyük çoğunluğunun erişkin yaş grubunda, \%53.8'inin 30-64 yaş arasında olduğu görülmüştür ${ }^{4}$. Literatür verileri ve çalışma sonuçlarımız değerlendirildiğinde, tularemi olguları her dönemde erişkin yaş grubunda daha fazla görülmüştür ve bu durum 
kırsal kesimde tarım ve hayvancılık ile uğraşan erişkinlerin, kontamine su ve gıdalarla daha fazla temasının olması ile açıklanabilir. Tularemi klinik formları değerlendirildiğinde Türkiye verileri ile uyumlu olarak en sık orofaringeal formun görüldüğü saptanmıştır. Türkiye'de kontamine su ve gıdaların, tularemi bulaşının ana kaynağı olduğu düşünüldüğünde ${ }^{2}$, orofaringeal formun baskın form olarak saptanması şaşırtıcı olmamıştır.

Ülkemizde tularemi sonbahar ve kış aylarında daha sık görülmektedir. 1936-2011 yılları arasında literatürde bildirilmiş olan olguların \%91.5'i Ağustos ve Mart ayları arasında görülmüştür ${ }^{4}$. Çalışmamızda Yozgat ilinde tularemi olgularının en sık kış aylarında ikinci sıklıkta ise ilkbahar aylarında olduğu görülmektedir. Coğrafi olarak Yozgat ile komşuluğu bulunan Kayseri ilinde yapılan benzer bir çalışmada da tularemi olgularının kış aylarında daha sık görüldüğü saptanmıştır ${ }^{12}$.

Çalışmamızda, 2010-2011 yıllarında Yozgat'ta görülen tularemi salgınının mevsimsel değişkenlerle ilişkisinin saptanması amaçlanmıştır. İlim değişikliği ile zoonotik hastalıkların ilişkisi tıp literatüründe geniş bir yer tutan evrensel bir konudur ${ }^{3}$. Dünyamız insan aktivitesinin sebep olduğu sera gazı emisyonuna bağlı olarak ısınmaktadır. Son 100 yılda dünyamız yaklaşık $0.75^{\circ} \mathrm{C}$, son 25 yılda her dekat başına $0.18^{\circ} \mathrm{C}$ ısınmıştır ${ }^{13}$. İlim değişikliği vektör biyolojisini ve hastalık bulaşını etkilemekle birlikte, vahşi lagomorf ve rodent popülasyonu ve davranışlarını da etkilemektedir ${ }^{3}$. Tularemi epidemiyolojisindeki değişikliğin ise ekolojik değişikliklere ve iklim değişikliklerine bağlı olduğu düşünülmektedir ${ }^{11,14}$.

Tularemi olguları ile iklim faktörleri ve iklim değişikliği arasındaki ilişkiyi araştıran yayınlar incelendiğinde, Türkiye'den yapılmış bir çalışma dikkat çekmektedir. Kayseri bölgesinde görülen salgının yağmurlu dönem sonrası gelişen düşük nem ve yüksek sıcaklıkla ilişkili olduğu vurgulanmıştır ${ }^{12}$. İsveç'te iklim değiş̧ikliği senaryosu ile 2010-2100 yılları yaz aylarında yaklaşık $2^{\circ} \mathrm{C}$ artış ile tularemi salgın sürelerinde 3.5 ile 6.6 hafta arasında artış olacağı öngörülmüştür ${ }^{15}$. İsveç'te tulareminin ana bulaş yolunun sivrisinekler olduğu bilindiğinden ve ülkemizde sivrisineklerin tularemi vektörü olduğu henüz kanıtlanamadığından bu senaryo sonucunun ülkemiz için geçerliliği tartışmalıdır. Palo ve arkadaşları ${ }^{16}$ ise, iklim ve tularemi tanısı olan insan olguları arasında anlamlı ilişki olduğunu, İsveç'te soğuk kışların ve nehirlerde düşük su akımının insanlarda görülen tularemi olgularında artışa neden olabileceğini fakat yaz aylarının daha sıcak olması ile artış beklenmeyeceğini belirtmişlerdir. Rusya'da (Russian Arctic) ise 1955-2000 yılları arasında yıllık ortalama sıcaklığın $1.2^{\circ} \mathrm{C}$ arttığı ve 2007 yılından itibaren Arkhangelsk Bölgesindeki tularemi prevalansının sıcaklık artışına bağlı olarak 100.000'de 2'ye ulaştığı bildirilmiştir ${ }^{17}$. Ermenistan'da 2003 yılındaki su kaynaklı ve 2007 yılındaki gıda kaynaklı tularemi salgınları incelendiğinde, salgınların görüldüğü bölgelerin rakımının 1400-2300 m olduğu, salgınların kuru ve ılıman yaz ayları ve soğuk kış ayları ile ilişkili olduğu bildirilmiştir ${ }^{18}$. Alaska'da son 60 yılda yıllık ortalama sıcaklığın $1.6^{\circ} \mathrm{C}$ arttığı ve iklim değişikliğinin etkisi ile kene ve kemiricilerin dağılımı ve sayısal artışı ile tularemi olgularının artmasının beklendiği belirtilmiştir ${ }^{19}$. Azerbaycan'da yapılan bir çalışmada ise tularemi insidansının, kuru hava ile ters orantılı, yıllık yağış miktarı ile doğru orantılı olarak arttığı bildirilmiştir ${ }^{20}$. 
Çalışmamızda ise, salgın görülen yıllar ile diğer yıllar karşılaştırıldığında, ortalama sıcaklık, yağış miktarı ve nem oranı açısından anlamlı bir fark saptanmamıştır. Bununla birlikte rüzgar şiddeti salgın görülen yıllarda diğer yıllara oranla istatistiksel olarak anlamlı derecede yüksek bulunmuştur $(p<0.05)$. Literatür incelendiğinde tularemi olguları ile rüzgar hızının doğrudan ilişkilendirildiği bir çalışma bulunamamıştır. Rüzgar hızının kene popülasyonu üzerine etkisini gösteren çok sayıda çalışma vardır ve artan rüzgar hızının, nimflerin yayılmasına ve hem kene sayısı hem de kene dağılımı üzerine etkisi olduğuna vurgu yapılmaktadır ${ }^{21,22}$. Ülkemizde tularemi bulaşında keneler ön planda değildir ve çoğunlukla kontamine su ve gıdalarla tularemi bulaştığı bilinmektedir. Nadir bildirilen olgu serilerinde kenelerin de Türkiye'de tularemi bulaşına neden olduğu gösterilmiştir. Yeşilyurt ve arkadaşları ${ }^{23}$, Yozgat ilinde kene kaynaklı iki tularemi olgusu bildirmişlerdir. Olgulardan birisinde ise kaynak olan kenenin Dermacentor spp. olduğu belirlenmiştir. Düzce bölgesinden bildirilen 22 tularemi olgusunun üç tanesinde kene teması olduğu ve ülseroglandüler tularemi geliştiği bildirilmiştir ${ }^{24}$. Kars bölgesinde ise Dermacentor türü kenelerden fare inokülasyonu deneyi ile F.tularensis izole edilmiş ve bu tür kenelerin koyunlara tularemi bulaşında vektör olduğu kanıtlanmıştı ${ }^{25}$. Kenelerin tulareminin yaşam döngüsünde hem vektör hem de rezervuar oldukları bilinmektedir ${ }^{4}$. Çalışmamızda, tularemi salgınının görüldüğü 2010-2011 yıllarında rüzgar hızının diğer yıllara oranla anlamlı derecede yüksek olduğu saptanmıştır ve bu yükseklik kene popülasyonunun sayısında ve dağılımında artışa neden olmuş olabilir. Artan kene popülasyonunun, tulareminin insanlara doğrudan bulaşından çok, kemirici ve evcil hayvanlara (küçükbaş hayvan, memeliler vb.) bakteri geçişini sağlayarak, tulareminin yaşam döngüsünün devamlılığında anahtar rol oynadığını düşünüyoruz.

Çalışmamız, Türkiye'nin iç Anadolu Bölgesinde yer alan Yozgat ilini kapsayan kesitsel bir çalışmadır. Olgu sayımız çok olsa da çalışmanın coğrafi olarak küçük bir bölgeyi kapsaması ve vektör dağılımını etkileyen faktörlerin tümünü ele almadan, meteorolojik değişkenlere odaklanması, bu çalışmanın kısıtlı yönlerindendir. Bu kısıtlılığa rağmen iklimsel değişikliklerin, enfeksiyon hastalıkları sıklığı ve dağılımı üzerine etkileri göz önüne alındığında, gelecekteki salgınları öngörmede ve önlemede çalışmamız ve benzeri çalışmaların verilerini ve oluşturdukları farkındalığı önemsiyoruz. Daha geniş coğrafi alanlarda ve tüm faktörleri içeren kapsamlı çalışmalara ihtiyaç olduğunu düşünüyoruz.

\section{ÇIKAR ÇATIŞMASI}

Yazarlar bu makale ile ilgili herhangi bir çıkar çatışması bildirmemişlerdir.

\section{KAYNAKLAR}

1. Penn RL. Francisella tularensis (Tularemia), pp: 2590-602. In: Mandell GL, Bennett JE, Dolin R (eds), Mandell, Douglas and Bennett's Principles and Practice of Infectious Diseases. 2015, $8^{\text {th }}$ ed. Churchill Livingstone, Philadelphia.

2. Ulu Kılıc A, Kılıc S, Sencan I, Cicek Sentürk G, Gürbüz Y, Tütüncü EE, et al. A water-borne tularemia outbreak causedby Francisella tularensis subspecies holarctica in Central Anatolia region. Mikrobiyol Bul 2011; 45(2): 234-47. 
3. Fears RMV. Human and animal health in Europe: the viewfrom the European Academies Science Advisory Council (EASAC) on challenges in infectious disease. Italian J Public Health 2012; 9(2): 5-12.

4. Gürcan Ş. Epidemiology of tularemia. Balkan Med J 2014; 31: 3-10.

5. Gotschlich E, Berkin T. 1936 yılında Trakya'da tularemiye ait yapılan epidemiyolojik ve bakteriyolojik araştırmalar. Turk Hij Tecr Biyol Derg 1938; 1: 115-23.

6. Morand S, Owers KA, Waret-Szkuta A, Mclntyre KM, Baylis M. Climate variability and outbreaks of infectious diseases in Europe. Scientific Reports 2013; 3: 1774.

7. Dirik K. Van Gölü havzasında Tularemie. Turk Hij Tecr Biyol Derg 1939; 2: 193-5.

8. Golem SB. Lüleburgaz'da yeni bir tularemi epidemisi. Turk Hij Tecr Biyol Derg 1945; 5: 27-40.

9. Utku iE. Antalya'da tularemi epidemisi ve hususiyetleri. Turk Hij Tecr Biyol Derg 1954; 14: 288-93.

10. Helvaci S, Gedikoglu S, Akalin H, Oral HB. Tularemia in Bursa, Turkey: 205 cases in ten years. Eur J Epidemiol 2000; 16: 271-6.

11. Kılıç S. Francisella tularensis ve Türkiye'de tularemi epidemiyolojisine genel bir bakış. FLORA 2010; 15: 37-58.

12. Balci E, Borlu A, Kilic AU, Demiraslan H, Öksüzkaya A, Doganay M. Tularemia outbreaks in Kayseri, Turkey: an evaluation of the effect of climate change and climate variability on tularemia outbreaks. J Infect Public Health 2014; 7(2): 125-32.

13. WHO. Protecting health from climate change: global research priorities; 2009. http://www.who.int/ publications/2009/9789241598880 eng.pdf (Erişim Tarihi: 15.09.2019).

14. Akalın H, Helvacı S, Gedikoğlu S. Re-emergence of tularemia in Turkey. Int J Infect Dis 2009; 13(5): 547-51.

15. Ryden P, Sjostedt A, Johansson A. Effects of climate change on tularaemia disease activity in Sweden. Glob Health Action 2009; 2: 10.

16. Palo TR, Ahlm C, Tärnvik A. Climate variability reveals complex events for tularemia dynamics in man and mammals. Ecol Soc 2005; 10(1): 22.

17. Revich B, Tokarevich N, Parkinson AJ. Climate change and zoonotic infections in the Russian Arctic. Int J Circumpolar Health 2012; 71: 18792.

18. Melikjanyan S, Palayan K, Vanyan A. Human cases of tularemia in Armenia, 1996-2012. Am J Trop Med Hyg 2017; 97(3): 819-25.

19. Hueffer K, Parkinson AJ, Gerlach R, Berne J. Zoonotic infections in Alaska: disease prevalence, potential impact of climate change and recommended actions for earlier disease detection, research, prevention and control. Int J Circumpolar Health 2013; 72:10.

20. Clark DV, Ismailov A, Seyidova E, Hajiyeva A, Bachishova S, Hajiyev $H$, et al. Seroprevalence of tularemia in rural Azerbaijan. Vector Borne Zoonotic Dis 2012; 12(7): 558-63.

21. Urdaz Rodriguez J, Fosgate G, Alleman AR, Rae O, Donovan A, Binford M, et al. Association between ecological factors and the presence of Rhipicephalus (Boophilus) microplus larvae in Puerto Rico. Exp Appl Acarol 2012; 58(2): 145-57.

22. Li S, Heyman P, Cochez C, Simons L, Wanwambeke S. A multi-level analysis of the relationship between environmental factors and questing Ixodes ricinus dynamics in Belgium. Parasit Vectors 2012; 5: 149.

23. Yeşilyurt M, Kılıç S, Çağaşar Ö, Çelebi B, Gül S. Yozgat ilinde kene kaynaklı iki tularemi olgusu. Mikrobiyol Bul 2011; 45: 746-54.

24. Sencan I, Sahin I, Kaya D, Oksuz S, Ozdemir D, Karabay O. An outbreak of oropharyngeal tularemia with cervical adenopathy predominantly in the left side. Yonsei Med J 2009; 50(1): 50-4.

25. Şeyda T. Kars bölgesinde koyunlarda tularemi infeksiyonunun insidensi üzerinde serolojik ve kültürel çalışmalar: ilk rapor. Kafkas Üniv Vet Fak Derg 1996; 2(1): 49-60. 